\title{
Direct Versus Indirect Remedies for Externalities
}

\section{Citation}

Green, Jerry, and Eytan Sheshinski. 1976. Direct versus indirect remedies for externalities. Journal of Political Economy 84(4): 797-808.

\section{Published Version}

http://dx.doi.org/10.1086/260477

\section{Permanent link}

http://nrs.harvard.edu/urn-3:HUL.InstRepos:3204666

\section{Terms of Use}

This article was downloaded from Harvard University's DASH repository, and is made available under the terms and conditions applicable to Other Posted Material, as set forth at http:// nrs.harvard.edu/urn-3:HUL.InstRepos:dash.current.terms-of-use\#LAA

\section{Share Your Story}

The Harvard community has made this article openly available.

Please share how this access benefits you. Submit a story.

\section{Accessibility}




\title{
Direct versus Indirect Remedies for Externalities
}

\section{Jerry Green}

\author{
Harvard University
}

\section{Eytan Sheshinski}

Hebrew University of Jerusalem, Jerusalem, and Stanford University

This paper is concerned with tax policies designed to obtain an improved competitive allocation in the presence of consumption externalities. It is known that the full optimum can, in general, be attained only through the imposition of excise taxes at different levels for different individuals. Since these may be ruled out (possibly because of implementation costs), one is confined to consider second-best taxes. The common interpretation of the Pigouvian principle has called for taxes on the externality-creating commodities. With no relationships between the consumption of different commodities the Pigouvian principle is obviously impeccable. But the existence of substitutes or complements for an externality-causing commodity raises the possibility of indirect policies: treating the externality through the markets for related goods. Obviously, if the direct policy is not feasible, the indirect treatment may provide some partial remedy. We show, however, that even when direct policies are available, the overall optimum may involve only indirect policies. An example with such a result is provided in the paper. We also list a number of cases in which the traditional prescription is confirmed, and the overall optimum involves only direct policies.

The economic analysis of situations involving externalities has focused on two related issues. The first is the comparison between competitive equilibrium and Pareto-optimal allocations, while the second concerns tax policies designed to obtain an improved competitive allocation. The degree of improvement depends, of course, on the scope of the

The work of the first author was supported by NSF grant GS-31688 at Harvard University, and of the second author by NSF grants GS-35890 at the University of California at Berkeley, and SOC-74-11446 at Stanford University. 
available fiscal instruments and on the form of the externalities. It is known that the full optimum can, in general, be attained only through the imposition of excise taxes at different levels for different individuals. As we shall show below, a notable exception to this rule is the case of consumption externalities which depend on the total consumption of certain commodities by the economy provided that individuals disregard the effect of their actions on the level of externalities. In this case, which Meade (1952) appropriately termed "atmosphere" externalities, ordinary commodity taxes are sufficient for achievement of the full optimum. This type of externality is the analog of the perfectly competitive model, because in the large-numbers case the individual would be correct in neglecting the influence of his consumption on the level of the externality in the aggregate. In more general cases, for example, with a small number of consumers or with large numbers but asymmetries in individuals' behavior or in externality generation, policies discriminating between individuals are required for attaining a full Pareto optimum. Since these may be ruled out (possibly because of implementation costs), one is confined to consider second-best taxes. This is the case treated in this paper.

The problem of the optimal tax policy is to determine the commodities upon which taxes are imposed (or subsidies granted) and the optimum levels of these taxes. The Pigouvian principle (Pigou 1932, pp. $192 \mathrm{ff}$.), accepted by all writers (see, for example, Baumol [1972] and the references therein), has been to impose a tax/subsidy on the generator of the externality. In the case of nonreciprocal negative production externalities (smoke affecting costs of neighboring laundries), this is achieved by imposition of effluent charges aimed at restricting output of the externality-creating factor. In the case of reciprocal consumption externalities, the common interpretation of the Pigouvian principle calls for taxes on the externality-creating commodities. Again, Davis and Whinston (1962), Plott (1966), Buchanan (1969), and others have shown that according to this principle anomalous cases cannot be ruled out. For example, with negative externalities an improvement may be realized by granting a subsidy rather than imposing a tax.

This literature has completely neglected the question of the proper variables to be taxed (or subsidized). With no relationships between the consumption of different commodities the Pigouvian principle is obviously impeccable. But the existence of substitutes or complements for an externality-causing commodity raises the possibility of indirect policies: treating the externality through the markets for related goods. Thus, if cars create smog, one remedy may be to tax goods complementary with car trips (such as recreation).

It seems plausible that indirect policies are in general inferior to direct policies. In the international trade literature, for example, one finds 
statements that in the presence of market distortions (which may be viewed as a kind of externality) direct fiscal policy in these markets is always superior to indirect policies (Johnson 1972).

On the basis of a more general model, we reach a different conclusion. Obviously, if the direct policy is not feasible, the indirect treatment may provide some partial remedy. We show, however, that even when direct policies are available, the overall optimum may involve only indirect policies. An example with such a result is provided below. Diamond (1973) has a similar example where the direct policy fails, but he has not considered the possibility of indirect policies. We also list a number of cases in which the traditional prescription is confirmed and the overall optimum involves only direct policies.

\section{The Model}

We consider a model which has two consumers who purchase an externality-causing good $\alpha$ and a related good $\beta$, among other commodities. To rule out income effects we assume that utility is linear in income net of expenditures on $\alpha$ and $\beta$. The unit costs of $\alpha$ and $\beta$ are $p$ and $q$. Policies considered in this paper are per unit taxes/subsidies on consumption of $\alpha$ and $\beta$, denoted $t$ and $z$, respectively. Consumers face prices $p+t$ and $q+z$ for these goods, and maximize their utility functions given by

$$
\begin{aligned}
& U=u\left(\alpha_{1}, \beta_{1}, \alpha_{2}\right)+X_{1}+T_{1}, \\
& V=v\left(\alpha_{2}, \beta_{2}, \alpha_{1}\right)+X_{2}+T_{2},
\end{aligned}
$$

where $X_{i}=I_{i}-(p+t) \alpha_{i}-(q+z) \beta_{i}, i=1,2, I_{i}$ are exogenous incomes of the two individuals, and $T_{i}$ are lump-sum transfer payments, representing a redistribution of tax revenues.

Note that in this formulation the individual's consumption choices of $\alpha$ and $\beta$ are independent of his money income and his lump-sum taxes, $T_{i}$.

The transfer payments are thought of as proportional redistributions of the tax revenue. If $\theta$ is the share of individual 1 in the taxes collected,

$$
\begin{aligned}
& T_{1}=\theta\left[t\left(\alpha_{1}+\alpha_{2}\right)+z\left(\beta_{1}+\beta_{2}\right)\right], \\
& T_{2}=(1-\theta)\left[t\left(\alpha_{1}+\alpha_{2}\right)+z\left(\beta_{1}+\beta_{2}\right)\right] .
\end{aligned}
$$

The first-order conditions for the individuals' maximization problems, assuming that the others' actions are fixed, are

$$
\begin{array}{ll}
u_{1}=p+t, & v_{1}=p+t, \\
u_{2}=q+z, & v_{2}=q+z .
\end{array}
$$

It is clear that competitive equilibria with $t=z=0$ are generally 
inefficient. The goals of this study are to evaluate the comparative efficacy of $t$ and $z$ as policy tools and to investigate the seemingly intuitive presumption that direct corrective taxation is a superior tool.

\section{Negative Result}

In this section we present an example showing that indirect taxation may be a useful policy while direct measures are impotent. To do this we demonstrate that $t^{*}=0$ is the optimal direct tax when $z=0$ and that $z^{*} \neq 0$ is the optimal indirect tax when $t=0$. A fortiori, the resulting allocation, when indirect taxes are used, is superior.

Consider the case of a direct tax, and let

$$
\begin{aligned}
& U=\mathscr{U}(\theta, t), \\
& V=\mathscr{V}(\theta, t),
\end{aligned}
$$

be the realized values of utility in an equilibrium in which $t$ and $\theta$ are the policy parameters. These functions can be depicted as in figure 1 .

The dashed curves are iso- $U$ loci in the $(t, \theta)$ space. A positive slope indicates $d \mathscr{U} / d t<0$, since $d \mathscr{U} / d \theta$ is always positive. Restricting ourselves to the policy variables $\theta$ and $t$, a constrained Pareto optimum is characterized as a maximum of $\mathscr{U}+\mathscr{V}$, with respect to these variables. Since there are no income effects, we have $(d \mathscr{U} / d \theta) \equiv-(d \mathscr{V} / d \theta)$.

This explains why all such constrained optima $\left(\theta^{*}, t^{*}\right)$ are determined by $t^{*}$ alone, since any $\theta$ would satisfy the first-order conditions. The first-order condition for an optimal $t^{*}$, which is therefore the only operative condition, is given by

$$
\frac{d \mathscr{U}\left(\theta^{*}, t^{*}\right)}{d t}=-\frac{d \mathscr{V}\left(\theta^{*}, t^{*}\right)}{d t} .
$$

In particular, the optimal $t$ may be found by setting both sides of the last equation to zero. However, since neither $\alpha$ nor $\beta$ levels are affected by changes in transfers, this equation continues to hold for all $\theta$. All Pareto optima are associated with the same $t^{*}$, as depicted in figure 1 .

Zero will be the optimal tax if

$$
0=\frac{d \mathscr{U}(\theta, 0)}{d t}
$$

and

$$
0=\frac{d \mathscr{V}(\theta, 0)}{d t}
$$

for some $\theta$.

Let $\bar{\theta}_{1}$ and $\bar{\theta}_{2}$ be the solutions of (8) and (9). Then, $t^{*}=0$ requires $\bar{\theta}_{1}=\bar{\theta}_{2}$. 


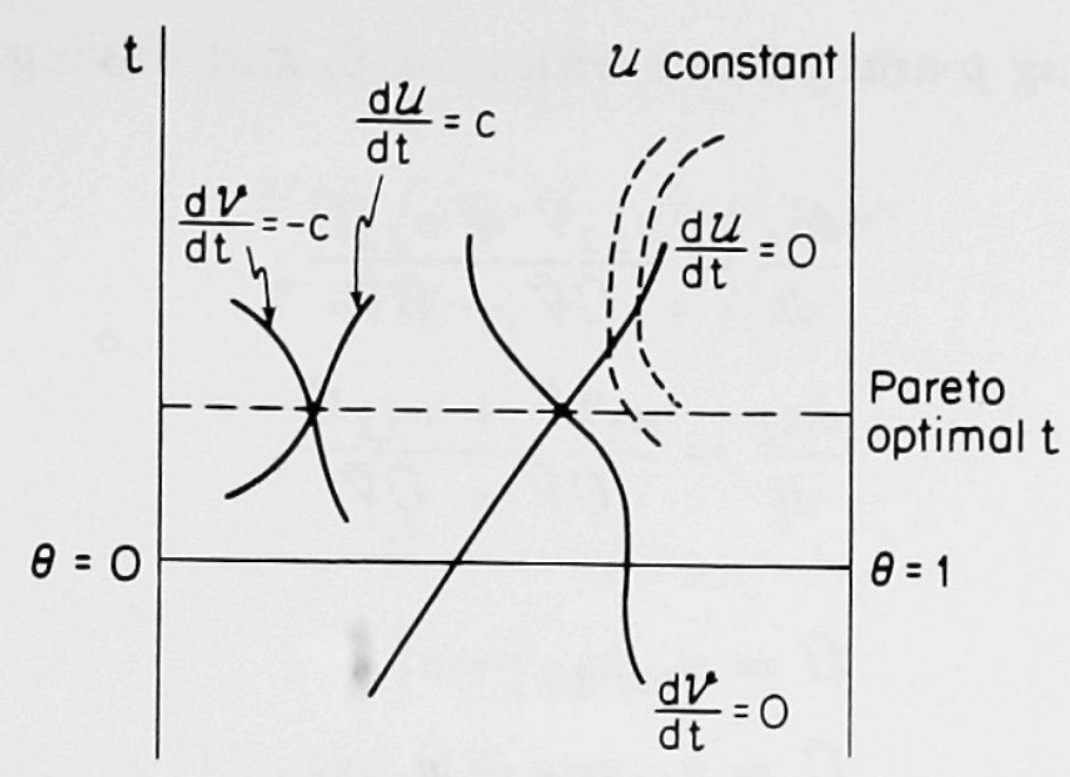

Fig. 1

Differentiating the $\mathscr{U}$ and $\mathscr{V}$ totally with respect to $t$ using the budget constraints obtained by substituting (3) and (4) into (1) and (2), and making use of the first-order conditions (5), one can derive

$$
\begin{aligned}
& \bar{\theta}_{1}=\frac{\alpha_{1}-u_{3}\left(d \alpha_{2} / d t\right)}{\alpha_{1}+\alpha_{2}} \\
& \bar{\theta}_{2}=\frac{\alpha_{1}+v_{3}\left(d \alpha_{1} / d t\right)}{\alpha_{1}+\alpha_{2}},
\end{aligned}
$$

where $d \alpha_{i} / d t$ is the total derivative of consumption with respect to $t$, including the change induced through an altered level of the externality, in equilibrium. In the case of an externality that is harmful to both individuals, it should be noted that $\bar{\theta}_{1}=\bar{\theta}_{2}$ will be satisfied if (exactly) one of the individuals increases his consumption of the externality-causing good in response to increases in the tax-that is, if $d \alpha_{1} / d t$ and $d \alpha_{2} / d t$ have opposite signs.

One can regard the change in demand as being composed of two parts. First, there is a direct effect of price, holding the externality fixed, which amounts to a pure-own substitution effect (movement along a given demand curve). Since there are no income effects, this must be negative. Second, there is the effect of the altered level of the other individual's consumption at constant prices, the sign of which depends on the crossderivative of utility with respect to these arguments. If a higher level of the externality induces a greatly increased level of demand, this may outweigh the first effect and produce a positive total derivative with respect to $t .^{1}$ The example of this section has this property, as will be seen below.

Differentiating the first-order conditions (5) with respect to the $\alpha$ 's,

1 This is related to the perverse behavior of aggregate consumption of the externality generating good between equilibria and Pareto optima, as discussed in Diamond and Mirrlees (1973). 
$\beta$ 's, and $t$, holding $p$ and $q$ fixed with $z=0$, and solving for $d \alpha_{1} / d t$ and $d \alpha_{2} / d t$, we have

$$
\begin{aligned}
& \frac{d \alpha_{1}}{d t}=\frac{u_{22} \hat{V}+v_{22} \tilde{U}}{U \hat{V}-\tilde{U} \tilde{V}}, \\
& \frac{d \alpha_{2}}{d t}=\frac{u_{22} \tilde{V}+v_{22} \tilde{U}}{\hat{U} \hat{V}-\tilde{U} \tilde{V}},
\end{aligned}
$$

where

$$
\begin{aligned}
& \hat{U}=u_{11} u_{22}-u_{12}^{2}, \\
& \tilde{U}=u_{12} u_{23}-u_{13} u_{22}, \\
& \hat{V}=v_{11} v_{22}-v_{12}^{2} \\
& \tilde{V}=v_{12} v_{23}-v_{13} v_{22} .
\end{aligned}
$$

Note that $\hat{U}$ and $\hat{V}$ are positive due to the second-order conditions. The terms $\tilde{U}$ and $\tilde{V}$ are related to the effects of the externality on the two goods in question.

We have, therefore, that $\bar{\theta}_{1}=\bar{\theta}_{2}$ if

$$
u_{3}\left(u_{22} \tilde{V}+v_{22} \tilde{U}\right)+v_{3}\left(u_{22} \hat{V}+v_{22} \tilde{U}\right)=0 .
$$

Similarly, $\mathscr{U}^{\prime}(\theta, z)$ and $\mathscr{V}^{\prime}(\theta, z)$ are the utilities attained when only indirect taxation is allowed, and $\theta_{1}^{\prime}$ and $\theta_{2}^{\prime}$ are defined by

$$
0=\frac{d \mathscr{U}^{\prime}\left(\theta_{1}^{\prime}, 0\right)}{d z}=\frac{d \mathscr{V}^{\prime}\left(\theta_{2}^{\prime}, 0\right)}{d z}
$$

The optimal $z$ will be different from zero whenever $\theta_{1}^{\prime} \neq \theta_{2}^{\prime}$. Following the analysis above,

$$
\begin{aligned}
& \frac{d \alpha_{1}}{d z}=\frac{u_{12} \hat{V}+v_{12} \tilde{U}}{-\tilde{U} \hat{V}+\tilde{U} \tilde{V}} \\
& \frac{d \alpha_{2}}{d z}=\frac{u_{12} \tilde{V}+v_{12} \tilde{U}}{-\hat{U} \hat{V}+\tilde{U} \tilde{V}} .
\end{aligned}
$$

Condition (14) is therefore

$$
u_{3}\left(u_{12} \tilde{V}+v_{12} \tilde{U}\right)+v_{3}\left(u_{12} \hat{V}+v_{12} \tilde{U}\right) \neq 0,
$$

where all derivatives are evaluated at the consumption levels of the untaxed equilibrium. Rewriting (13) and (16) we have

$$
\begin{aligned}
& \tilde{V}=\frac{-v_{22}}{u_{22}} \hat{U}-\frac{v_{3}}{u_{3}} \hat{V}-\frac{v_{3} v_{22}}{u_{3} u_{22}} \tilde{U} \\
& \tilde{V} \neq \frac{-v_{12}}{u_{12}} \tilde{U}-\frac{v_{3}}{u_{3}} \hat{V}-\frac{v_{3} v_{12}}{u_{3} u_{12}} \tilde{U} .
\end{aligned}
$$


To show that (17) and (18) can be consistent, let $U$ and $V$ have the forms

Thus,

$$
\begin{aligned}
& U=f\left(\alpha_{1}, \beta_{1}\right)+g\left(\alpha_{2}\right), \\
& V=h\left(\alpha_{2}, \alpha_{1}\right)+j\left(\beta_{2}\right) .
\end{aligned}
$$

$$
\begin{aligned}
& \tilde{U}=0, \\
& \tilde{V}=-v_{13} v_{22}, \\
& \hat{V}=v_{11} v_{22} .
\end{aligned}
$$

Hence, conditions (17) and (18) are

and

$$
\begin{gathered}
\left(\frac{v_{3}}{u_{3}} v_{11}-v_{13}\right)=\frac{-\hat{U}}{u_{22}}, \\
v_{22} \neq 0,
\end{gathered}
$$

$$
0 \neq 0 \text {. }
$$

Since $v_{3}, u_{3}$ and $v_{11}$ are all negative, we can show that these relations may be satisfied when evaluated at points that would be chosen in a competitive economy without taxes. This is done by selecting a value for $u_{3}$ to satisfy (20), having fixed all of the other functions. Because of the separable functional form of $U$, this can be done without disturbing either of the relationships (21) or (22). In order to be sure not to violate the nonpositivity of $u_{3}$ in doing so, we require

$$
v_{13}<\frac{\hat{U}}{u_{22}}
$$

It is therefore necessary to show only that the functions $f$ and $h$ can be chosen so as to satisfy (23). Let us take

$$
\begin{aligned}
& f\left(\alpha_{1}, \beta_{1}\right)=\alpha_{1}^{a_{1}} \beta_{1}^{b_{1}}, a_{1}+b_{1}<1 ; a_{1}, b_{1}>0 ; \\
& h\left(\alpha_{2}, \alpha_{1}\right)=\alpha_{2}^{a_{2}} \alpha_{1}^{-c}, 1>a_{2}>0 ; c>0 .
\end{aligned}
$$

One can show that

$$
v_{13}=-c p\left(\frac{p}{a_{1}}\right)^{(2 c+1)\left(1-b_{1}\right) /\left(1-a_{1}-b_{1}\right)}\left(\frac{q}{b_{1}}\right)^{(2 c+1) b_{1} /\left(1-a_{1}-b_{1}\right)}
$$

If $p>a_{1}$ and $q>b_{1}$, then $v_{13}$ becomes arbitrarily large and negative as $c$ becomes large. Further, the equilibrium values of $\alpha_{1}$ and $\beta_{1}$ are independent of $c$; hence $\hat{U} / u_{22}$ is fixed. Therefore we can choose $c$ sufficiently large and will obtain the desired example.

Two further remarks need to be made in this context. We have not shown that the only solutions to the first-order conditions are of the form 
$t^{*}=0, z^{*} \neq 0$. However, we have placed no restrictions on $u_{3}=g^{\prime}\left(\alpha_{2}\right)$ except at the point given by the choice of $\alpha_{2}$ with zero tax rates on both commodities. One can easily see that by choosing $g^{\prime}\left(\alpha_{2}\right)$ appropriately at other values, it can be arranged that (19) is not satisfied at any nonzero $t$. Hence the local character of this example can be extended globally to imply that no direct commodity taxation can improve the laissezfaire equilibrium, although indirect methods are effective.

Second, one might want to know the sign of the tax (subsidy) in the market for $\beta$ which is superior to any direct taxation on $\alpha$. Suppose the externality is harmful so that $u_{3}, v_{3}<0$ and that $\alpha$ and $\beta$ are complements in the ordinary sense of a negative cross-elasticity of demand. Here we would expect a positive tax level to be the optimal indirect action, tending to reduce the level of the externality.

A positive $z$ will be optimal if, at $z=0$, we have $\left(\partial \mathcal{U}^{\prime} \mid \partial z\right)>-\left(\partial \mathscr{V}^{\prime} \mid \partial z\right)$ where $\mathscr{U}^{\prime}$ and $\mathscr{V}^{\prime}$ are as described above.

This is equivalent to $\theta_{1}^{\prime}<\theta_{2}^{\prime}$. Or, following an analogous derivation to equations (10) and (11), this is,

$$
-u_{3} \frac{d \alpha_{2}}{d z}<v_{3} \frac{d \alpha_{1}}{d z}
$$

Substituting (15) in the above we have

$$
u_{3} \frac{u_{12} \tilde{V}+v_{12} \tilde{U}}{\hat{U} \hat{V}-\tilde{U} \tilde{V}}+v_{3} \frac{u_{12} \hat{V}+v_{12} \tilde{U}}{\hat{U} \hat{V}-\tilde{U} \tilde{V}}<0 .
$$

Since $\tilde{U}=0$ in the above example, and $\hat{U} \hat{V}>0$ by the second-order conditions, we have

$$
u_{3}\left(u_{12} \tilde{V}+v_{12} \tilde{U}\right)+v_{3} u_{12} \tilde{V}<0
$$

is the condition for $z^{*}$ to be positive.

Using (16), since $t^{*}=0$ in the example, this becomes

$$
\theta\left(\frac{-v_{22} u_{12} u_{3}}{u_{22}}+u_{3} v_{12}\right)<0
$$

Since $v_{12}$ is zero, this is surely violated in the example, and the optimal indirect tax has the perverse sign-positive for substitutes, negative for complements. However, more complex examples in which $v_{12} \neq 0$ may provide instances in which the sign of $z^{*}$ has the expected behavior and indirect taxation is still superior. This remains as an open question.

\section{Positive Results}

Having seen that indirect corrective taxation is superior under certain conditions, we now turn our attention to the classification of conditions under which such aberrations are impossible. The general problem of the 
superiority of direct taxation will not be treated here. Our more modest results concern instances in which a zero tax on the related commodity is best, the optimum being to operate solely on the market of the externality-causing good even though more general policies are available. We will show that this is the case if individuals are identical, or if the externality depends on the aggregate consumption of the good in question, each individual neglecting his influence on this aggregate. Again, certain remarks concerning nonconvexities must be made, but we will demonstrate some instances in which our conclusions hold without qualification.

Let

$$
\begin{aligned}
& U=U(\theta, t, z), \\
& V=V(\theta, t, z),
\end{aligned}
$$

be the utility levels attained with taxes $t$ and $z$ and redistribution parameter $\theta$. By the linearity of utility in income, $W=U+V$ is independent of $\theta$. Necessary conditions for an optimal pair of taxes $\left(t^{*}, z^{*}\right)$ are

$$
\begin{aligned}
& 0=\frac{d W}{d t}=\left(v_{3}+t\right) \frac{d \alpha_{1}}{d t}+\left(u_{3}+t\right) \frac{d \alpha_{2}}{d t}+z\left(\frac{d \beta_{1}}{d t}+\frac{d \beta_{2}}{d t}\right) \\
& 0=\frac{d W}{d z}=\left(v_{3}+t\right) \frac{d \alpha_{1}}{d z}+\left(u_{3}+t\right) \frac{d \alpha_{2}}{d z}+z\left(\frac{d \beta_{1}}{d z}+\frac{d \beta_{2}}{d z}\right),
\end{aligned}
$$

all derivatives being evaluated at the points chosen with taxes $\left(t^{*}, z^{*}\right)$. One can solve these conditions for $t$ and $z$ at the optimum. This yields

$$
\begin{gathered}
z^{*}=\frac{\left[\left(d \alpha_{1} / d z\right) \cdot\left(d \alpha_{2} / d t\right)-\left(d \alpha_{1} / d t\right) \cdot\left(d \alpha_{2} / d z\right)\right]\left(v_{3}-u_{3}\right)}{\left[\left(d \alpha_{1} / d t\right)+\left(d \alpha_{2} / d t\right)\right]\left[\left(d \beta_{1} / d t\right)+\left(d \beta_{2} / d t\right)\right]} . \\
-\left[\left(d \alpha_{1} / d z\right)+\left(d \alpha_{2} / d z\right)\right]\left[\left(d \beta_{1} / d z\right)+\left(d \beta_{2} / d z\right)\right]
\end{gathered}
$$

Substituting (12) and (15) in (33), one finds that

$$
z^{*}=0, \quad \text { if } v_{3}=u_{3} \text { or } \quad v_{12} u_{22}=u_{12} v_{22} \text {. }
$$

Two special instances in which these conditions hold are when individual's preferences are identical, or when they are separable in $\beta$. In general, however, the optimal policy will involve taxes/subsidies in indirect markets. Even in the case of identical utilities the foregoing conclusion depends on the fact that individuals will have identical consumptions in equilibrium.

Fixing prices and taxes, we can think of each individual's choice of $\alpha$ as it depends on the level of the externality he faces. This gives rise to two identical reaction functions, the intersections of which are equilibrium consumptions of $\alpha$ for this model. We wish to establish that this equilibrium is unique and occurs at a symmetric point. That is, we want to establish conditions for these reaction curves to be as in case (1) rather than case (2), in figure 2. 




FIG. 2

A condition for this uniqueness to hold is that the slope of the reaction curve be between 0 and -1 everywhere. This will hold if utility can be written in the form

$$
u\left[f\left(\alpha_{i}, \alpha_{1}+\alpha_{2}\right), \beta_{i}\right], \quad i=1,2 .
$$

The interpretation of such a functional form is that the externality takes the form of aggregate consumption and affects the effective consumption of services $\alpha$, but not $\beta$. In this context it is natural to assume that simultaneous equal increases in the consumption of $\alpha$ by both individuals does not increase the effective level for both of them. Such an upward variation in $\alpha_{1}$ and $\alpha_{2}\left(d \alpha_{1}=d \alpha_{2}\right)$ changes $f$ by $f_{1} d \alpha_{1}+f_{2}\left(d \alpha_{1}+d \alpha_{2}\right)$. Therefore we require

$$
f_{1}+2 f_{2}>0 \text {. }
$$

The individual's first-order conditions are

$$
\begin{array}{r}
u_{1} f_{1}=p+t \\
u_{2}=q+z .
\end{array}
$$

Differentiating totally, the slope of the individual's reaction curve is shown to be

$$
\frac{d \alpha_{i}}{d \alpha_{j}}=\frac{f_{2}}{f_{1}+f_{2}} .
$$

By (36) this is shown to be between 0 and -1 as desired.

In the foregoing analysis we have assumed that the individual takes into account the full impact of his actions on his utility. However, particularly in the case of a large number of consumers, it may be more natural to assume that consumption has direct benefits and also contributes to an externality-causing aggregate. The individual may be ignoring his marginal contribution to this aggregate. This form of externality has been termed "atmosphere" by Meade (1952), who found that direct 
taxation on the components of this aggregate could lead to a Pareto optimum. In the context of the above analysis

$$
\begin{aligned}
& U=\phi\left(\alpha_{1}, \beta_{1}, \alpha_{1}+\alpha_{2}\right)+X_{1}+T_{1}, \\
& V=\psi\left(\alpha_{2}, \beta_{2}, \alpha_{1}+\alpha_{2}\right)+X_{2}+T_{2} .
\end{aligned}
$$

The assumption that individuals disregard their contribution to the externality is reflected in the equilibrium conditions

$$
\begin{array}{ll}
\phi_{1}=p+t, & \psi_{1}=p+t \\
\phi_{2}=q+z, & \psi_{2}=q+z .
\end{array}
$$

One should be careful in comparing (40) with the rather similarlooking conditions (5). The utility functions (1) and (12) are different from (39) in their behavioral implications because there the individual's own consumption of $\alpha$ affects his utility in a way that he takes account of explicitly. In (39) and (40) he optimizes with respect to his choice of $\alpha$ by setting the derivative of utility with respect to its first argument equal to price but does not subtract the effect of $\alpha$ through the third argument. If the same behavioral hypothesis in (39) were taken, we would have had $\phi_{1}+\phi_{3}=\psi_{1}+\psi_{3}=p+t$, instead.

Letting $W=U+V$ we find that

$$
\begin{aligned}
d W=\left(\phi_{1}\right. & \left.+\phi_{3}\right) d \alpha_{1}+\phi_{2} d \beta_{1}+\phi_{3} d \alpha_{2}+\left(\psi_{1}+\psi_{3}\right) d \alpha_{2} \\
& +\psi_{2} d \beta_{2}+\psi_{3} d \alpha_{1}-p\left(d \alpha_{1}+d \alpha_{2}\right)-q\left(d \beta_{1}+d \beta_{2}\right) .
\end{aligned}
$$

Using the first-order condition (40),

$$
d W=\left(t+\phi_{3}+\psi_{3}\right) d \alpha_{1}+\left(t+\phi_{3}+\psi_{3}\right) d \alpha_{2}+z\left(d \beta_{1}+d \beta_{2}\right) .
$$

Thus $t^{*}=-\phi_{3}-\psi_{3}, z^{*}=0$ solves the optimization problem even though both direct and indirect tax policies are available.

Following Diamond (1973), a more general form of atmosphere-type externalities is given by the utility functions

$$
\begin{aligned}
& U=\phi\left[\alpha_{1}, \beta_{1}, \gamma\left(\alpha_{1}, \alpha_{2}\right)\right]+X_{1}+T_{1}, \\
& V=\psi\left[\alpha_{2}, \beta_{2}, \gamma\left(\alpha_{1}, \alpha_{2}\right)\right]+X_{2}+T_{2},
\end{aligned}
$$

for some function $\gamma$. As above, individuals are assumed not to perceive their influence on the level of $\gamma$, so that first-order conditions for their maximization problems are given by $(40)$.

Differentiating $W$ with respect to $t$ and $z$, a necessary condition for the optimal $z^{*}$ to be zero is

$$
\left(\gamma_{1}-\gamma_{2}\right)\left(\frac{d \alpha_{1}}{d z} \frac{d \alpha_{2}}{d t}-\frac{d \alpha_{1}}{d t} \frac{d \alpha_{2}}{d z}\right)=0
$$

In the additive case $\gamma_{1}=\gamma_{2}$, and (44) is always satisfied. This will 
also hold in the case of identical individuals in the absence of additivity (see above).

It will also hold, even if individuals are not identical, provided their relative changes in the consumption of the externality-causing commodity with respect to the two taxes are equal; that is

$$
\frac{\left(d \alpha_{1} / d t\right)}{\left(d \alpha_{1} / d z\right)}=\frac{\left(d \alpha_{2} / d t\right)}{\left(d \alpha_{2} / d z\right)}
$$

More generally, if (44) holds at a point where

$$
t^{*}=\frac{\left(\phi_{3}+\psi_{3}\right)\left[\left(d \alpha_{1} / d t\right) \gamma_{1}+\left(d \alpha_{2} / d t\right) \gamma_{2}\right]}{\left[\left(d \alpha_{1} / d t\right)+\left(d \alpha_{2} / d t\right)\right]},
$$

and $z^{*}=0$, then this is an optimum. Notice that (44) and (45) imply that $z^{*}=0$ only when

$$
\frac{\gamma_{1}\left(d \alpha_{1} / d t\right)+\gamma_{2}\left(d \alpha_{2} / d t\right)}{\left(d \alpha_{1} / d t\right)+\left(d \alpha_{2} / d t\right)}=\frac{\gamma_{1}\left(d \alpha_{1} / d z\right)+\gamma_{2}\left(d \alpha_{2} / d z\right)}{\left(d \alpha_{1} / d z\right)+\left(d \alpha_{2} / d z\right)}
$$

which means that the sum of marginal externalities, weighted by quantity response to direct price change $(t)$ is equal to the sum of marginal externalities weighted by quantity response to indirect price change $(z) .^{2}$

\section{References}

Baumol, W. J. "On Taxation and the Control of Externalities." A.E.R. 62 (June 1972): 307-22.

Buchanan, J. M. "External Diseconomies, Corrective Taxes, and Market Structure." A.E.R. 59 (March 1969): 174-77.

Davis, O. A., and Whinston, A. "Externalities, Welfare, and the Theory of Games." J.P.E. 70 (June 1962): 241-62.

Diamond, P. A. "Consumption Externalities and Imperfect Corrective Pricing." Bell J. Econ. and Management Sci. 4 (Autumn 1973): 526-38.

Diamond, P. A., and Mirrlees, J. A. "Aggregate Production with Consumption Externalities." Q.J.E. 87 (February 1973): 1-24.

Johnson, H. G. Aspects of the Theory of Tariffs. Cambridge, Mass.: Harvard Univ. Press, 1972.

Meade, J. E. "External Ecónomies and Diseconomies in a Competitive Situation." Econ. J. 62 (March 1952): 59-67.

Pigou, A. C. The Economics of Welfare. 4th ed. London: Macmillan, 1932.

Plott, C. R. "Externalities and Corrective Taxes." Economica 33 (February 1966): 84-87.

${ }^{2}$ We owe this observation to Peter Diamond. 
Copyright of Journal of Political Economy is the property of University of Chicago Press and its content may not be copied or emailed to multiple sites or posted to a listserv without the copyright holder's express written permission. However, users may print, download, or email articles for individual use. 